\title{
Qualitative Improvement in Composition and Letter Writing Proficiency for Primary School Leavers in Botswana: Documenting Perspectives of the Teacher
}

\author{
Mogapi, M. ${ }^{1}$ \\ ${ }^{1}$ Educational Foundations, University of Botswana, Botswana \\ Correspondence: Mogapi, M., Educational Foundations, University of Botswana, Botswana. E-mail: \\ molefhe.mogapi@mopipi.ub.bw
}

Received: November 25, 2013 Accepted: January 21, $2014 \quad$ Online Published: June 5, 2014

doi:10.5430/ijelt.v1n2p42 URL: http://dx.doi.org/10.5430/ijelt.v1n2p42

\begin{abstract}
The need to maintain consistent standards from year to year is very important as consistent standards provide an avenue for ensuring that learners receive quality education. Teachers, as main facilitators within the learning teaching environment, are better placed to monitor the quality of education. The views and opinions of the teachers are important in determining whether there is an improvement, stagnation or deterioration in the general performance of learners over time. The paper therefore attempts to develop a trend analysis of the language proficiency level of primary school candidates in process writing. A sample of 50 teachers was selected from population of over 500 teachers enrolled in the Department of Primary Education for 2012 -2013 academic year. Both quantitative and qualitative data analysis methods were used to answer the research questions.
\end{abstract}

Keywords: Language Proficiency Educational Productivity Model, Thematic Mapping

\section{Introduction}

The writing skill or the ability to communicate clearly and effectively is a very important component of national examinations, this perspective was expressed by Wagemaker, Hans., Taube, Karin., Munck, Ingrid., Kontogiannopoulou-Polyorides, George \& Martin, Michael when they stated that "considerable proportion of school resources are therefore devoted to it, education researchers suggest that literacy might also play an important role in social and cultural reproduction" (1996, p. 78). At the end of the primary school cycle in Botswana, candidates seat for Primary School Leaving Examination (PSLE). A candidate's proficiency in use of English is assessed by means a multiple choice test and continuous writing paper made up of composition and letter writing. Though performance in the objective paper appears to be stable over time, the same cannot be said about composition and letter writing. Trend analysis for process writing from 1999 to 2002 indicate profound fluctuations from year to year (Mogapi, 2004). This phenomenon is depicted in Fig. 1 below.

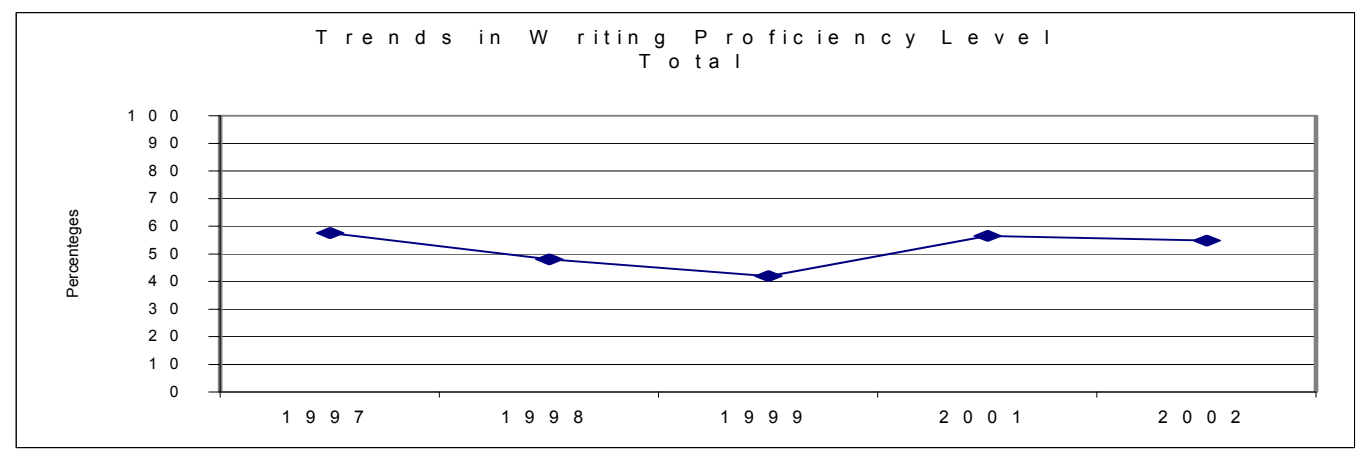

Figure 1. Trends in Continuous Writing from 1999 to 2002 


\section{Background}

There is increasing concern that quality of learning and teaching in schools is generally going down; the downward trend is being observed in primary, junior and secondary schools. The Minister of Education and Skills Development (MoESD) has recently alluded to this problem and also went as far as suggesting possible strategies that can be followed to arrest the situation. As a result, a committee made up of officers from curriculum development, public examinations department, primary and secondary departments has been constituted to look into the downward trend in students' performance in national examinations. The committee has been mandated to identify challenges and problems that lead to the decline in results, and to analyze and recommend solutions. (Botswana Daily News, Wednesday January 25, 2012, p. 1).

According to Wagemaker, et al., (1996), 'In today's world, cultural context for each country is a derivation of historical precedent, previous cultural manifestations and circumstances of economic and social development' (p. 78). Put in other words, the current observable disparities or shortcomings in the educational system have historical as well as socio-cultural origins. Specifically, socio-cultural environment directly influence reading literacy in a given country in the sense that they either create or impede opportunities for developing different literacy abilities. The current problem of fluctuating performance level in process writing has numerous sources but the main ones are teacher training and automatic promotion.

\section{Teacher Training}

Since independence in 1966, teacher training at the pre-service level was affected by two major constraints. Firstly, the selection criteria for prospective teachers was such that those who eventually enrolled to be trained as teachers for primary schools were required to have completed standard seven as the highest educational level. Therefore, the educational level for prospective teachers was very low as the following quote shows.

The quality of the teacher, both trained and untrained, leaves very much to be desired. The educational background of teachers is poor. Of the 1487 untrained teachers in 1976, 1204 or 81 percent had only Standard 7 education themselves. Of the 2434 trained teachers in the same year, 1365 (56 percent) had received only Standard 7 education before entering training colleges. Over half of the teachers in the Commission's survey indicated that they had some difficulty in speaking and understanding English. (Education for Kagisona, 1977, p. 67)

Secondly, the teacher training programme was only two years long at the end of which the completing candidate receives a Primary Teacher Certificate (PTC) that enabled him or her to teach in primary schools. The limited subject matter knowledge of the new teacher as well as short professional training programme had a negative impact on the teaching and learning of English Language in primary schools. The other factor that impacted negatively on the teaching and learning of English language was the high rate of untrained teachers in schools. From 1973 to 1979 the percentage of untrained teachers was consistently above $28 \%$ and in 1977 the proportion of untrained teacher reached a peak of $41 \%$ (Central Statistics as cited in NDP 5 p. 104). Therefore, a considerable number of language classes were handled by teacher who did not have the requisite tools to effectively deliver the content to the learners. This situation undoubtedly had far reaching and long lasting consequence on the performance of learners with respect to composition and letter writing,

\section{Automatic Promotion}

Automatic promotion of learners had to be used to increase efficiency in the system. However, automatic promotion proved to be a double edged sword as a large number of learners were pushed through the system without having learned the content specific to a grade. The negative effects of automatic promotion were highlighted in a review of educational progress done in 1977 known as Education for Kagisano. Thus, the following comment was made in the report; 'Many children are virtually illiterate at Standard Seven when they have nearly completed the primary course. The number who cannot read the most simple sentences is as high as thirty to forty percent'. (Education for Kagisona, 1977, p. 78)

\section{Statement of the Problem}

Maintaining comparable performance standards from year to year is critical not only for generation of meaningful grades but also necessary for the teachers, learners, education officers researchers, parents and other stakeholders to be able to establish the level of educational standards in a country. Random or unexplainable variations in performance levels from year to year makes it difficult for the schools and relevant authorities to be able to identify problem areas in order to devise intervention strategies aimed at addressing the problem. As such the problem for the study is 'Fluctuating performance standards for English Language composition and letter writing for Primary School 
Leaving Examination candidates in Botswana'. Major weaknesses observed in continuous writing (composition and letter writing) relate to correct use of tense, limited use of adjectives and conjunctions, coherence information, logical development of the story, sense of audience, paragraphing and the ability to come up with an appropriate register especially when writing business letters.

\section{Theoretical Frame Work}

The Educational Productivity Model was found to be relevant to the current topic. The model was developed by Herbert Walberg in 1981 after he did an extensive review of research studies that sought to identify key variables within schools that are significantly related to academic achievement of learners. Three environments were identifies and these are learners aptitude, the quality and quantity of instruction and the psychological environment within which the learner is operating. The three main factors have an interactive effect on the learner and are all depended on the quality of feedback information (Borg \& Gall, 1989).

The Educational Productivity allows for the identification and subsequent analysis of problem variables within an educational setting with a view to the design and implementation of relevant intervention strategies aimed at improving the quality of learning and teaching in schools. The current study will be focused on only two aspect; namely the classroom instruction and examination feedback information. The model was used to derive four research questions as indicated below.

\section{Research Questions}

1. Is there any significant improvement in English Language composition writing for PSLE candidates over a period of five years?

2. Is there any significant improvement in English Language letter writing for PSLE candidates over a period of five years?

3. Is there any significant differential performance in composition and letter writing by school location over a period of five years?

4. To what extent does examination feed back information influence learning of process writing

\section{Literature Review}

Teaching and learning of process writing is influenced by the relevance of the teacher training pre-service and in-service programmes and the quality of classroom instruction. According to a research done by Major and Tiro (2005) which was published in the Scientific Journal of Education; the researchers were interested in establishing the relation between pre-service teacher perception and the relevance of the teacher training programme that the teachers were currently going through. A total of 17 students were selected from third year students in one of the local teacher training colleges in Botswana. Perspective of the students regarding the relevance of the programme was collected using semi-structured interviews and classroom observations. The researchers made the following conclusion:

Most pre-service student teachers in the study expressed their dissatisfactory on the little time that they were given to practice the theories into real life situation. Even though the participants noted the importance of having enough content, they still felt that hands-on experience would make them better teachers when they graduate from the program. Participants indicated that teaching practice exposes them to real classroom experience that they will encounter as teachers. (Major \& Tiro, 2012, p. 68 )

The findings of this study lead the two researchers to recommend a review of the teacher training pre-service programme in order to increase the amount of time teacher trainees spend doing practical work in the classroom. This would increase the trainee teacher's effectiveness once they are practicing in schools.

The second important variable that has some influence on the effectiveness of English language teaching is in-service teacher education programme. Literature has informative research studies locally and internationally that looked at the relations between in-service training and teacher effectiveness as measured by learner performance. In a qualitative study done in 2006 by Moswela (2006), 15 public schools were selected randomly from a total of 233 junior and secondary schools in Botswana. Questionnaires were administered to school heads and in-service teachers in each of the 15 schools. In the end, the researcher came up with two key points relating to teacher in-service education. Firstly, the study established a link between good in-service training of teachers and learner performance. The researcher concluded that; '... as teachers improve their teaching skills and methodologies, students'standards of achievement are also raised, and this has an impact on schools'. (Moswela, 2006, p. 631). Another important finding 
from the study is that for an in-service training to be able to raise teacher effectiveness in the classroom, the training must focus on problems that the teachers are experiencing in schools. In other words, in-service workshops should serve the instructional needs of the learner and the teacher in the classroom The importance of this study does not only relate to the positive influence of in-service education on learner performance but the fact that in-service programme must be regular and focused on the instructional challenges that teachers are facing in the classroom.

Research studies done at the international level add an important dimension in understanding the relevance of in-service training. A multinational comparative study was done in Botswana, Lesotho and Swaziland; the purpose of this study was to assess the effectiveness of in-service training in each of the three countries. The results for the study were published in 1995. The major finding of the study was that some of schools in the three countries were manned by teachers 'who were either under qualified for the level they were actually teaching, or did not hold any teaching qualifications at all. This was particularly the case in Swaziland and Lesotho". Leo de Feiter \& Jan van den Akker (n.d. p. 5). The benefit of in-service training, therefore, is empowerment of the practicing teachers so that they can became effective and efficient practitioners. Effective teaching translates into improved learner performance. Another study that provides information on teacher in-service training in Botswana is the Southern and Eastern Africa Consortium for Monitoring Educational Quality (SACMEQ, 2005). This study was carried out in 2000 targeting primary school standard six pupils and their class teachers. The study shows that teachers attended an average of 2.7 in-service courses over a period of five years (SACMEQ, 2005). This translates into half a course per year or one course in two years. This also means that majority of teachers in the country to not have the opportunity to attend workshops that deal directly with problems or challenges they experience in the classroom. As a result teachers do not have the opportunity to frequently network with colleagues and other experts in the field so as to discuss and share ideas relating to the teaching of process writing. The direct effect of this is continued poor performance in the composition and letter writing examinations.

The last part of the literature review focus on establishing the current process writing skills of primary learners in Botswana. The current knowledge status of learners is directly related to the quality of teaching and learning going on in schools. A number of large scale studies have been done with an objective to establish the base line data indicating the knowledge status of learners. Two studies have been consulted and these are; Monitoring Learning Achieving and Trends [MLA] and Southern and Eastern African Consortium for Monitoring Education (SACMEQ)

Monitoring Learning Achieving and Trends [MLA]

The objectives of MLA research study conducted by Examinations Research and Testing Division of the Ministry of Education in Botswana was "to assess the level of attainment of pupils in Standard Four and to gather information of the factors that facilitate or hinder learning" (Republic of Botswana, 2000, p. 6). The study targeted 10\% of the recorded 737 primary schools in Botswana; therefore, 70 schools were eventually sample and each standard four class in each of the 70 schools was included in the sample. This resulted in a total of 5788 pupils in 172 classes (Republic of Botswana, 2000). One interesting piece of information is the low performance in writing and written expression; the recorded scores were $43.5 \%$ and $4.33 \%$ for writing and writing expression respectively(Republic of Botswana, 2000).. The written expression is particularly low and a cause of concern.

\section{Southern and Eastern African Consortium for Monitoring Educational (SACMEQ)}

SACMEQ is a research body that is made up of 15 countries in Sub Sahara Africa and it is coordinated by International Institute for Educational Planning (IIEP). The 15 countries are Botswana, Kenya, Lesotho, Malawi, Mauritius, Mozambique, Namibia, Seychelles, South Africa, Swaziland, Tanzania (Mainland), Tanzania (Zanzibar), Uganda, Zambia, and Zimbabwe. The different ministry of education in the 15 countries periodically conduct large scale research studies in collaboration with IIEP to determine the level of educational attainment for children in primary schools. SACMEQ officers use the data collected to produce country reports that reflect indicators of the quality of basic education for each country.

Data in Botswana was collected using a questionnaire and a test. The questionnaire solicited information about the school and home background of learners whilst the test assessed content mastery level. Efforts were made to make sure that the test was congruent with the content (domains) and behaviours (skills) derived from detailed analyses of the curricula, syllabi, exams, and textbooks used in the SACMEQ countries ( SACMEQ, 2005). The population for the SACMEQ study was the standard 6 learners in Botswana attending public schools. This produced a total population of 41292 from 606 schools in Botswana. Stratified sampling was used to take into consideration regional variations. The SACMEQ data collection exercise was done in September 2000 in all the educational district. 


\section{SACMEQ Findings}

The SACMEQ study generated a number of important findings relating to pupil achievement levels, learner achievement by gender and learner achievement by school location. Performance on the test was judged on the basis of whether pupils attained minimum or desirable mastery level in relation to a pre-determined performance scale based on objectives from the syllabus. It was established that most learners in Botswana did well with respect to minimum level objectives (55.8\%) while only $15.7 \%$ reached the desirable level ones (SACMEQ, 2005).In conclusion the following comment was posted:

These percentages are generally low, and the message is that, while Standard 6 pupils in Botswana were a little above the SACMEQ mean, more than two-fifths of them still failed to reach what the SACMEQ experts deemed to be the minimum standards and more than four-fifths failed to reach the desirable standards set by the experts. It should also be a matter of concern to the Ministry that such large proportions of pupils in Central North, Central South and West regions failed to reach minimum and desirable levels of mastery. (SACMEQ, 2005 p. 139).

The SACMEQ study also established that large cities like Gaborone consistently outperform all other regions followed by small towns. Learners in isolated or remote settlements are consistently at the bottom of the groups indicating poor performance or undesirable learning outcomes. Only $9.2 \%$ of remote area learners achieved mastery level as compared to $17.2 \%$ and $25.6 \%$ for small towns and large cities respectively (SACMEQ, 2005).

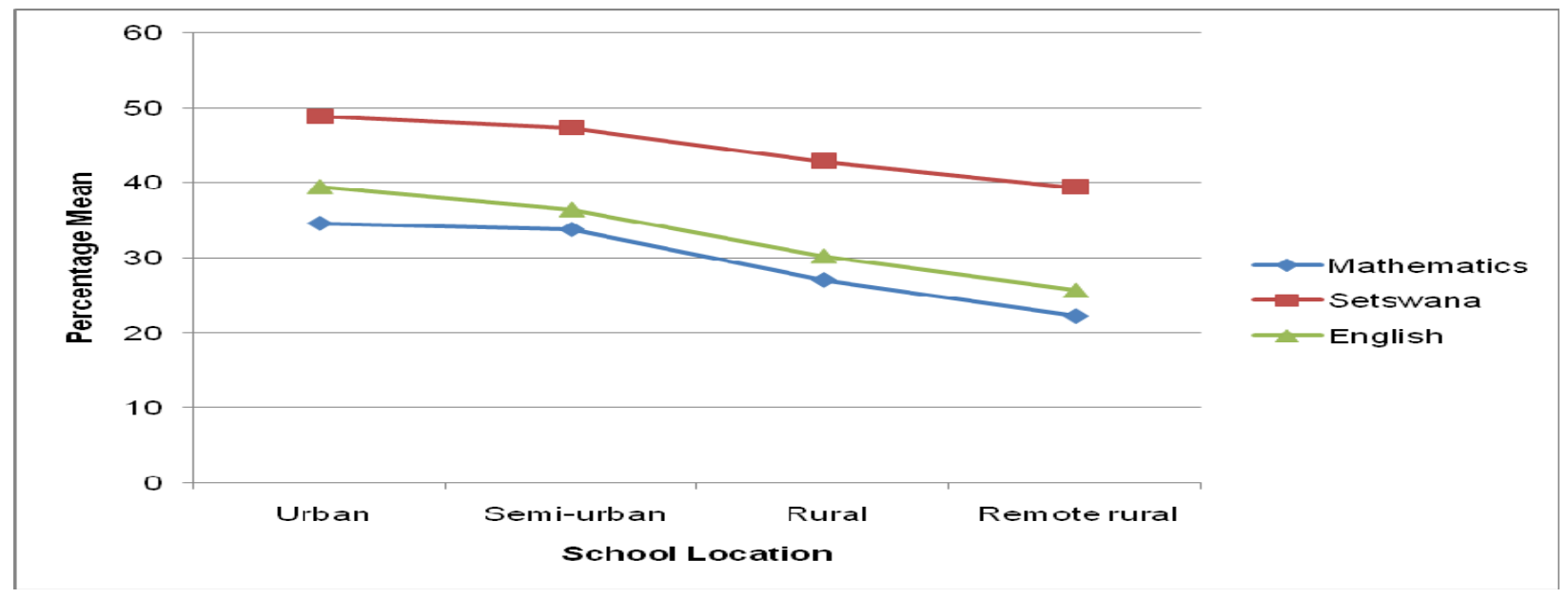

Figure 2. Pupil Achievement Level by School Location

Generally low level of teacher effectives in delivering the content to learners results in low performance. The connection between the quality of teaching and learning brings us back to the Theory of Educational Productivity. The theory postulates that the quality of instruction is one of the major factors that influence learner performance.

\section{Research Methodology}

The study is basically explorative aiming to establish whether there is prima facie evidence indicating qualitative improvement in the learning and teaching of process writing in Botswana primary schools in Botswana. The results of the study will therefore be used as a basis to launch a large scale country wide project to determine the extent to which performance.

\section{Population Characteristics}

The population for the study was all of the 500 primary school teachers who are currently studying for their first degrees in the Department of Primary Education, University of Botswana. The teachers were drawn from all educational districts in Botswana. Majority of these teachers had taught for more than five years and been engaged as final examinations markers.. A total of 50 teachers [ 26 males and 24 females] were sampled using simple random sampling procedures; this repersents $10 \%$ of the population. 


\section{Instrumentation}

The main data collection instrument used was the questionnaire. The questionnaire comprises both quantitative and qualitative items; the quantitative items are in the form of a likert scale that allows the teacher to indicate whether they Strongly Agree, Agree, Disagree or Strongly Disagree with the statement presented. Qualitative questions on the other hand require the respondents to explain or elaborate their answers; this will help in explaining the trends observed from 2008 to 2012.

\section{Data Collection}

The questionnaire was administered during the last week of March 2012. The data was then analyzed using SPSS version 18. The Cronbach Alpha reliability index for Part A of the questionnaire dealing with composition writing was .383 while Part B for Letter writing was .175. On the other hand, reliability coefficient for Par C relating to the 20 process writing indicators was .939 .

\section{Ethical Issues}

All the participants sampled were given the opportunity to state whether they were willing to participate in the study or not. Most of the teachers consented. The respondents were informed that findings and recommendations of the study would be used to improve the teaching and learning of process writing in primary schools in Botswana. Participants were informed in advance that the information they would provide would be kept confidential at all times and will be used only for the purpose of the study. Only serial numbers were used to make sure that the identity of the respond was not revealed.

\section{Quantitative Analysis: Likert Scale Items}

The presentation below show the percentage of teachers who strongly agreed, agreed, disagreed and strongly disagreed to the strongly under each item. Information under Fig. 5, Fig. 6 and Fig 7 was used to answer the first research question: Is there any significant improvement in English composition writing for PSLE candidates over a period of five years?

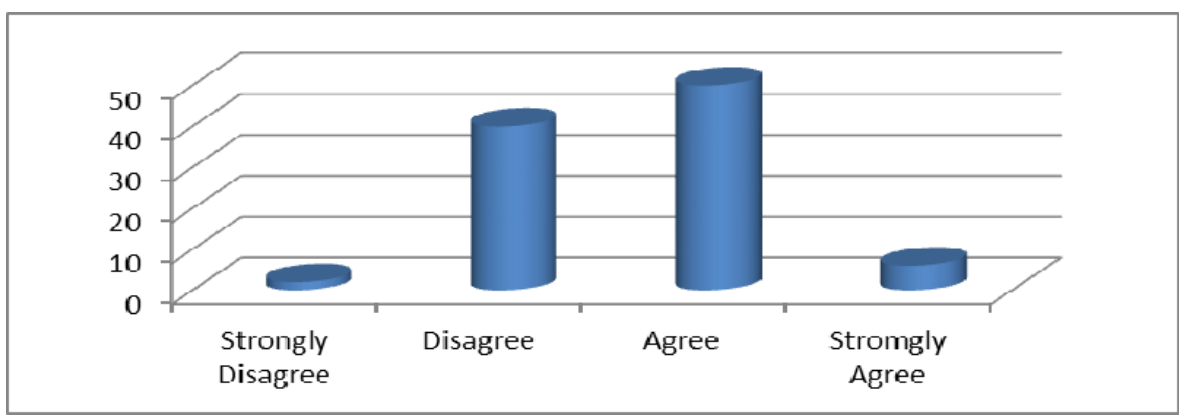

Figure 5. The quality of composition writing is improving over time: 2008 to 2012

The figure above shows that $50 \%$ of the teachers agreed that the quality of composition is improving over time. Only $2 \%$ strongly disagreed with the statement.

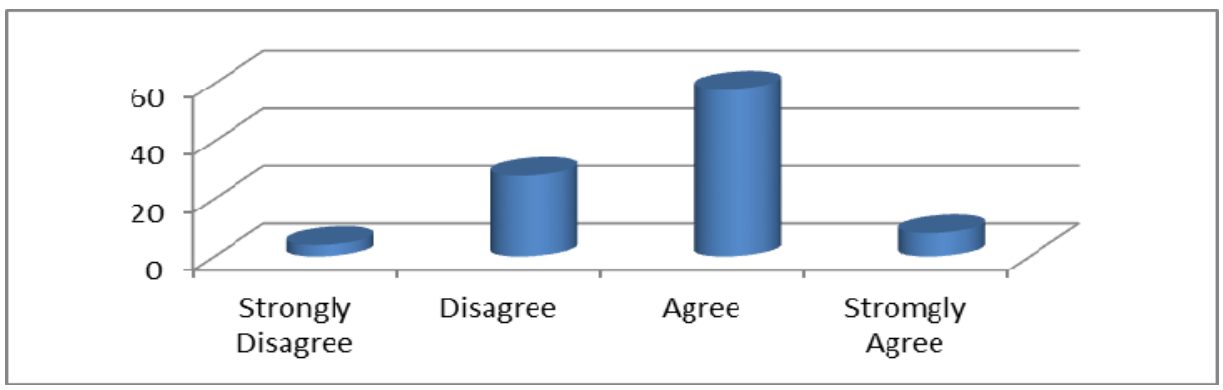

Figure 6. The quality of teaching is improving over time: 200 to 2012 
With respect to the quality of teaching, $58 \%$ agreed that it is improving over time as compared to $28 \%$ who disagreed with the statement.

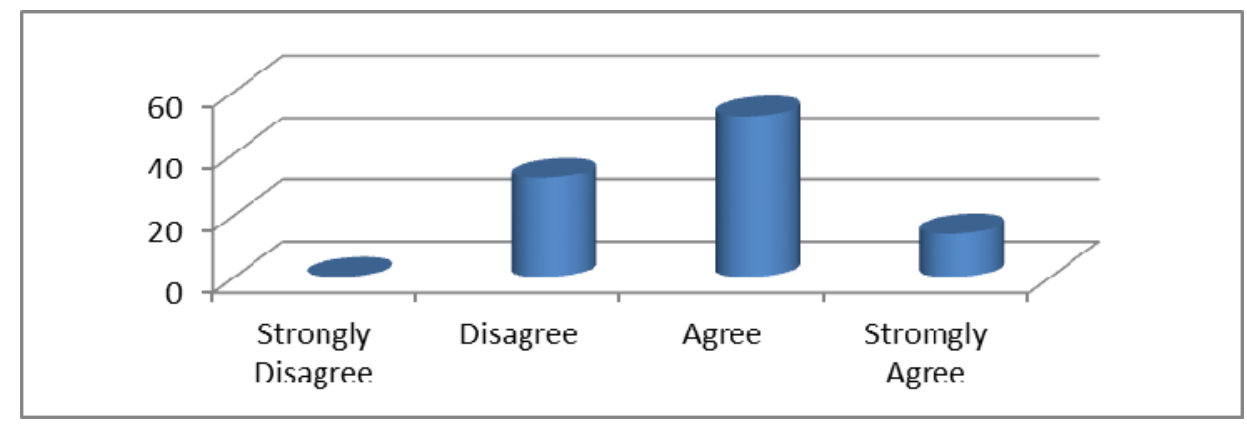

Figure 7. Common mistakes are repeated in the following years

The above figure shows that $66 \%$ of the teachers agreed that common mistakes made by candidates tend to be repeated year after years.

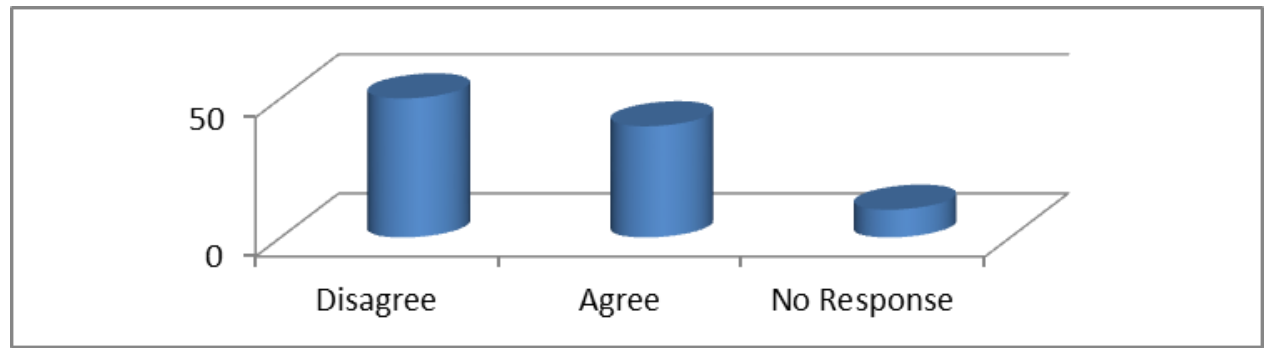

Figure 8. PSLE have become better writers over time: 2008 to 2012 General Quality

Surprisingly, $50 \%$ of the teachers disagree with the statement that says PSLE candidates have become better writers over time. The expectation was that a majority of the teachers will agree as they did under Fig. 5 and Fig. 6. The evidence presented so fat shows that teachers are not really sure as to whether improvement has taken place over the years. However, there is some credible evidence that suggests lack of improvement as a result of repetition of mistakes. For example, candidates might be using wrong tense from year to year.

\section{Letter Performance}

Information under Fig. 11 and Fig. 12 were used to answer the second research question relating to improvement in letter writing. The pattern of response to the letter variables is similar to the composition one. Teachers think that both the learning and teaching of this component has improved over time. Also, they have indicated that repetition of mistakes, workshops and text book content are issues that are lacking behind. The following analysis is for Process Writing (composition and letter writing combined) Indicators. Out of the 20 indicators selected, 13 were shown to have improved over time. The 7 indicators that have either gone down or remained the sane are presented below.

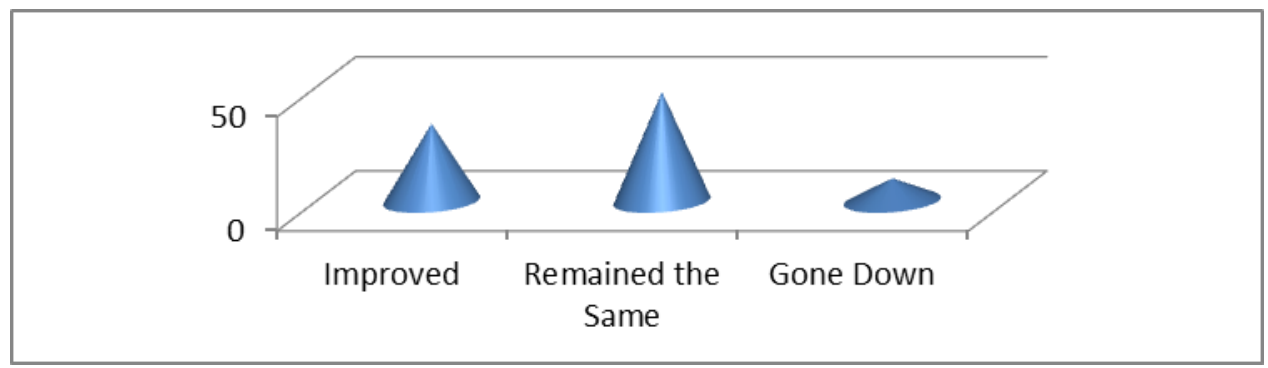

Figure 9. Ability to write coherently

Only $34 \%$ of the teachers have stated that writing a coherently has improved over time. 


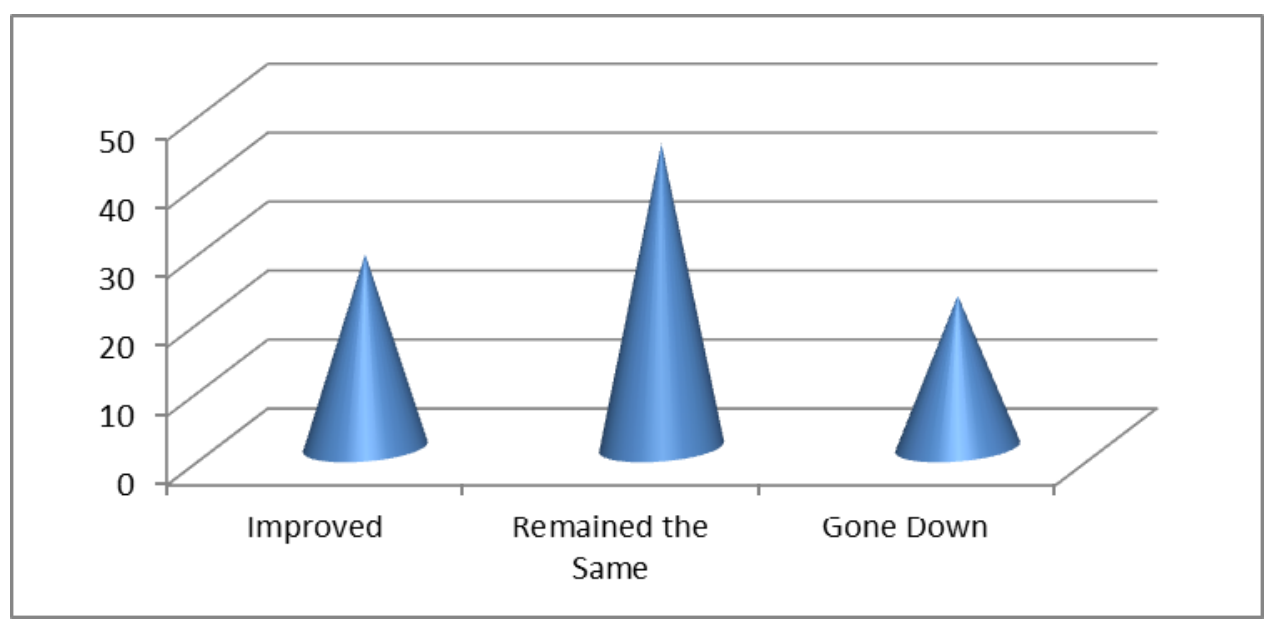

Figure 10. Correct use of adjectives

A total of $66 \%$ of the teachers believe that there is no improvement regarding correct use of adjectives. Only $28 \%$ are in the affirmative. Other indicators that have either stagnated or shown a down ward trend are correct use of conjunctions, correct use of tense and spelling of long words.

\section{Analysis of Qualitative Data}

Qualitative data was collected and analyzed to determine the extent to which school location influence performance (Research Question 3). The respondents were required to state whether they agreed or disagreed with a statement that said PSLE candidates become better writes over time. This item was followed by an open ended one that gave the respondent the opportunity to give more details regarding their choice. Thematic mapping technique was used to identify themes and other significant variables. The themes were aggregated by educational districts in Botswana.

\begin{tabular}{|c|c|c|}
\hline $\begin{array}{l}\text { Educational } \\
\text { District }\end{array}$ & $\begin{array}{l}\text { Factors that leads to improvement in } \\
\text { performance }\end{array}$ & $\begin{array}{l}\text { Factors that contribute to lack of improvement } \\
\text { performance }\end{array}$ \\
\hline Southern & $\begin{array}{l}\text { Workshops, Seminars, } \\
\text { Workshops for marking, }\end{array}$ & $\begin{array}{l}\text { Repetition of mistakes, little feedback, No feedback, } \\
\text { No feedback }\end{array}$ \\
\hline Ngami & $\begin{array}{l}\text { Teaching methods, drilling for exams, layout, } \\
\text { workshops, }\end{array}$ & $\begin{array}{l}\text { Self expression, results not divided by components, } \\
\text { No feed back }\end{array}$ \\
\hline Kweneng & ICT, workshops, guidelines, feed back, layout & $\begin{array}{l}\text { Repetition of mistakes, repetition of mistakes, } \\
\text { similar mistakes, business letters, fluctuating quality }\end{array}$ \\
\hline North East & Workshops, Examination practice & Emphasis on Paper 1, Repetition of mistakes, \\
\hline Central & $\begin{array}{l}\text { Guidelines, formatting letter, Feedback, } \\
\text { marking experience, teaching methods, } \\
\text { enthusiasm }\end{array}$ & $\begin{array}{l}\text { Repetition of mistakes, lack of marking experience, } \\
\text { remoteness of school, lack of creativity, answering } \\
\text { guidelines }\end{array}$ \\
\hline South East & $\begin{array}{l}\text { Tutoring, Project method, addressing main } \\
\text { points }\end{array}$ & \\
\hline Chobe & Workshops, mock exams, & No feedback \\
\hline Kgatleng & Private school influence & \\
\hline Ghantsi & & Cultural background \\
\hline
\end{tabular}

\section{Emerging Themes}

Figure 11. Thematic Mapping

Firstly, most teachers have observed that attending workshops improves their teaching which in turn improves performance of learners in the final examinations. However, workshop attendance is only open to senior teachers in 
schools. Therefore, schools with no senior teacher in English are denied the opportunity to attend. Secondly, teachers also noted that schools with teachers who are engaged as examiners for letter and composition tend to produce better results than schools that do not have examiners. Thirdly, there is an increasing usage of modern technology in schools; this is having some positive influence on performance of candidates. Lastly, schools in remote areas do not receive feedback information from Botswana Examinations Council regularly. Also, the remoteness of the school disadvantages the teachers when it comes to workshop attendance. This actually results in poor performance of candidates attending remote are schools. The other noted factor that contributes to poor results from remote schools is cultural background. Learners have to learn both Setswana and English during their first two years of schooling. This requirement presents a formidable barrier to learning.

Fig. 12 and Fig 13 below present information used to answer the last research question. Public examinations can be used to generate a lot of information indicating the strengths and weaknesses of candidates on a year to year basis. Such information can be used to run workshops for teachers to make them aware of the strengths and weaknesses of their learners. At the same time, examination feedback information can be used to improve the quality of text books and other learning resources. Systematic incorporation or infusion of examination feedback information in the learning and teaching process would result in the improvement of writing over the years.

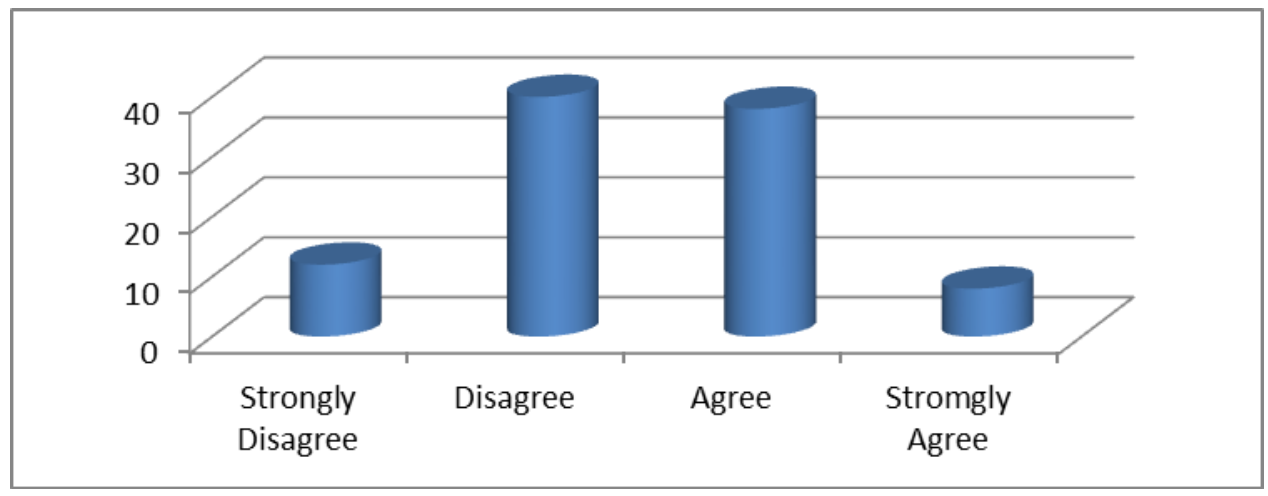

Figure 12. There are workshops held every year to discuss areas of weakness

A total of $52 \%$ of the teachers are of the view that workshops are not being held frequently to give teacher the opportunity to attend and discuss learner performance.

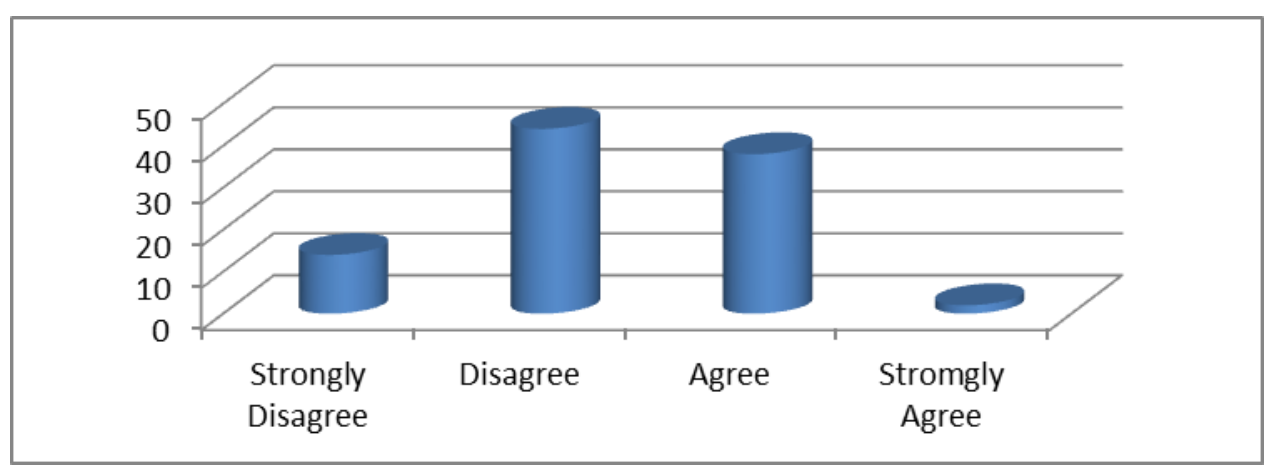

Figure 13. Text Book Content has been improves to address areas of weakness

Concerning content in the text books, $58 \%$ of the teachers say that content in the text books has not been improved to address areas of weakness showed by PSLE candidates. The information as presented under Fig. 12 and Fig. 13 depicts a situation where there is limited used of examination feedback information either to in-service teachers or improve the quality of text book content. Limited use of examination feedback information may result in the repetition of mistakes from year to year. If teachers are not aware of common mistakes made by candidates when writing composition and letter, such mistakes will be repeated from year to year. 


\section{Discussion}

According the Theory of Educational Productivity, performance of the learners is highly depended on the quality of the teaching environment. The teacher then becomes an important input because it is the teacher who organizes instruction and manages other input variables such as feedback information from tests and examinations. Majority of the respondents mentioned that performance on composition and letter writing is negatively influence by the tendency of students to repeat mistakes year and year. This is a multifaceted problem Firstly, repetition of mistakes means both the teacher and the leaner are not receiving feedback information from examining body showing the strength and weakness of candidates. Schools that do receive such feedback are able to work on the weakness area to improve performance in subsequent years. More effort should then be put in ensuring that examination feedback information reaches all schools as early as possible. Currently it appears that some schools in rural areas do not receive such information.

Secondly, repetition of mistakes may also point to an area of weakness on the part of the teacher. If the teacher is not competent in a particular skill or skills, it would become very difficult for the same teacher to impart the skills to the learners. Research has shown that there is a strong link between learner performance and vibrant in serve work. Teachers who constantly attend in-service workshops tend to produce good result if the workshop is based on the observed area of weakens shown by learners in the classroom (Moswela, 2006). The response of teachers indicated that workshops are provided for teachers but such workshops are only attended by senior teachers. Some of the senior teachers may already be engaged in some administrative work thus limiting their contact time with learners. This leads to the exclusion of a large majority of teachers who are actually in close contact with the learners.

The review of literature on pre-service teacher training programmes has also shown that teachers attribute their lack of skills or competency in a given area to their per-service training. It was observed earlier that majority of the teachers in primary schools went through a two year training programme after just completing seven tears of primary education. There is need to evaluate the pre-service programme so as to strengthen the qualification of completing teachers. Currently, the government is upgrading all diploma holding teachers to degree level, this will go a long way in improving the quality of teaching in schools. The other element that emanate from repetition of mistakes relates to text book production. Repetition of mistakes year after year actually means that content in the text books used in schools is some how deficient. If text book writers utilize information from exams then such mistakes will be minimized.

On a positive note, teachers have noted elements in the teaching and learning environment that have a positive impact over the years. Firstly, teachers who have been trained as markers for composition and letter have been able to assist their schools to improve. During marking of final examinations, makers go through intensive training to enable them to mark according to the marking scheme. This rigorous training actually helps the teacher to understand objectives in the syllabus better. As they mark the scripts, teachers also see the common mistakes made by candidates in the composition and letter. Such teachers then are a better position to assist their respective schools with the knowledge they gained from marking. The increasing usage of information technology in schools is another factor that contributes to improvement of performance over the years. As more students are exposed to the internet and other social media platforms, their ability to write fluently will improve. Teachers have also noted that vocabulary of students improve as a result of internet use.

\section{Conclusion}

The study has been able to identify major gaps in the system such as inadequate feedback loop to schools, preferential treatment given to senior teachers in workshop attendance, and lack of equity in the deliverance of education. On a positive note, the emergence of ICT in schools has already augmented traditional teaching methods.

\section{References}

Borg, Walter., \& Gall, Meredith. (1989). Educational research: An introduction. New York: Longman.

David, B., \& Resnick. (2011). What is Ethics in Research and Why is it important. retrieved from http://www.niehs.nih.gov/research/resources/bioethics/whatis.cfm

Duvan, Ibrahim. (2006). Analyzing education productivity: An essay review. Education Review, 9(4). Retrieved from http://www.edrev.info/essays/v9n4.pdf

Leo de Feiter, Hans Vonk, \& Jan van den Akker. (n.d.). Towards more effective science teacher development in 
Southern Africa. Retrieved from http://www.projects.edre.utwente.nl/smartnet/version2/cabinet/gfeiter.PDF

Major, T. E., \& Tiro, L. (2012). Theory Vs Practice: The case of primary teacher education in Botswana. International Journal of Scientific Research in Education, 5(1), 63-70. Retrieved from http://www.ijsre.com/Vol.,\%205_1_-Major\%20\%20\%20TYiro.pdf

Moswela, Bernard. (2006). Teacher professional development for the new school improvement: Botswana. International Journal of Lifelong Education, 25(6), 623-632. Retrieved from http://www.tamanproject.org/documentation/forum/share_your_resources/selection_post/teacher_profesional_d evelopment.pdf

Motsamai, Mmoniemang. (2012, January 25). Poor performance worries minister. Dailey News, Wednesday January, p. 1. Retrieved from http://www.eurojournals.com/ejsr_24_2_01.pdf

Republic of Botswana. (1997). Education for Kagisano. Gaborone: Government Printer.

Republic of Botswana. Education statistics: First term 2003. Central Statistics Office. Gaborone: Department of Printing and Publishing Services.

Republic of Botswana. (1979-1985). National Development Plan 5. Ministry of Finance and Development Planning. Gaborone: Government Printer.

Republic of Botswana. (2010). Ministry of Education and Skills Development. National In-service Teacher Training Policy framework. Retrieved from http://www.moe.gov.bw/fileadmin/templates/docs/TT_D/frame_works.pdf

Republic of Botswana. Ministry of Education. (2005). Trends in the international mathematics and science study. Examinations Research and Testing Division. Gaborone: Government Printer.

Republic of Botswana. Ministry of Education (2000). Report on the monitoring learning achievement project. Examinations Research and Testing Division. Gaborone: Government Printer.

Republic of Botswna. (2005). The SACMEQ II Project in Botswana: A study of the conditions of schools and the quality of education. Ministry of Education. Retrieved from http://www.sacmec.org.reports.htm

Squires, P. J. (2000). Perceptions of undergraduate diploma teachers concerning the usefulness of the course offered for training secondary agriculture education teachers at Botswana College of Agriculture. Journal of Agricultural Education, 41(3), 79-87. $\quad$ Retrieved from http://www.jae-online.org/attachements/article/432/41-30-80.pdf

Trochim, W. (2006). Ethics in research. Retrieved from http://www.socialresearchmethods.net/kb/ethics.php

Wagemaker, Hans, Taube, Karin., Munck, Ingrid., Kontogiannopoulou-Polyorides, George, \& Martin, Michael. (1996). Are girls better readers? Gender differences in reading literacy in 32 countries. The Hague: International Association for the Evaluation of Education achievement. 